\title{
9.3 Theoretical and methodological aspects of research and development of the enterprise management system
}

The current stage of development of Ukraine's economy requires a systematic approach to personnel management in industrial enterprises. Under the personnel management system is understood the multi-vector activity of the relevant personnel management services of the enterprise, which cover a number of functional subsystems of the production organization.

The personnel management system consists of six subsystems: subsystems of personnel management, subsystems of personnel marketing, subsystems of personnel development, subsystems of motivation of personnel, subsystems of management of communications, subsystems of creation and development of corporate culture. Depending on the size of the organization, the composition of the subsystem varies: in small and medium enterprises in one subsystem include the functions of several subsystems, and in large - the functions of each subsystem are performed by separate units. The combination of these subsystems is unique to each organization and determines its specificity.

Generalization of the experience of Ukrainian industrial enterprises (PJSC "Dnipro Metallurgical Plant", PJSC "Interpipe", PJSC "Evraz DMZ named after Petrovsky", etc.) allows to form the main goal of the personnel management system: ensuring the needs of the production process by employees of the required quality their effective use, professional and social development (Fig. 9.3.1).

This goal reflects the economic aspect of personnel management. In the social aspect, the purpose of personnel management is to meet the needs of employees. 


\section{Level 1 goals}

ensuring the needs of the production process by employees of the required quality, quantity and in a timely manner, the organization of their effective use, professional and social development

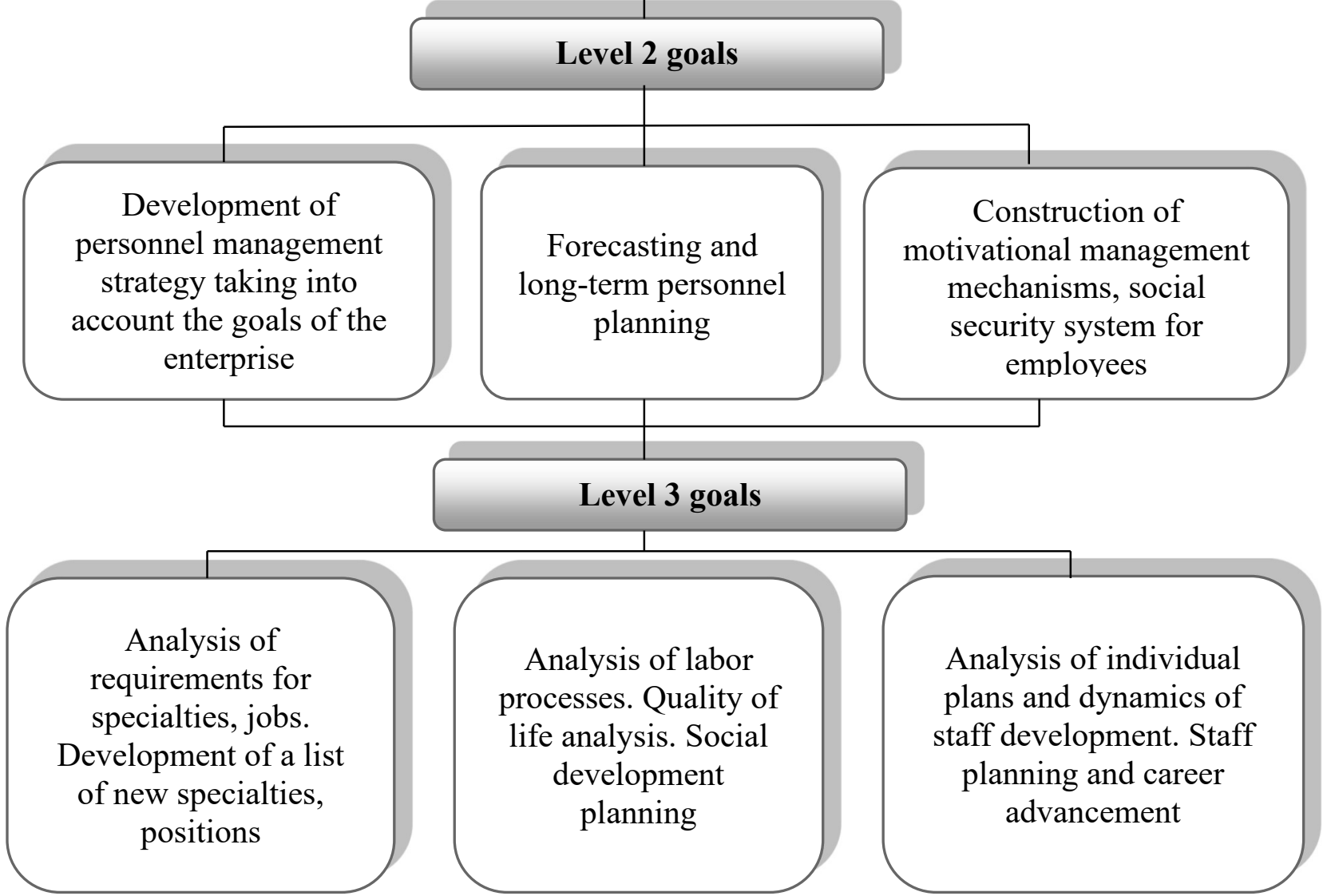

Figure 9.3.1. Tree of goals of the personnel management system of an industrial enterprise

Developed by the author based on sources [458-461]

The modern management of the enterprise is characterized by an adequate response to changes in market conditions, the development of new markets, areas of business. Therefore, research and development of personnel management system should take place through the use of sound principles, research methods, changes in management approaches, the choice of new forms and methods of implementing personnel policy, and so on.

The methodology of research of personnel management systems consists of theoretical provisions, principles, methods that most accurately reflect the features of 
this system. Knowledge of methodology is necessary for successful research and reliable results, which are the basis for the design, construction, organization and improvement of management systems.

In accordance with the objectives of the personnel management system is formed, and as a basis for its construction are used principles, ie rules and methods developed by science and tested in practice.

The principles of the study, being the most important category of methodology, are the basic rules, basis for action, essence and starting points used in the study.

Ignoring the principles of the study leads to unpredictability of results, errors and loss of time. As a result of the analysis of scientific and theoretical sources concerning management systems [462] the basic principles of research of a personnel management system are underlined and shown in fig. 9.3.2.

The principle of systematization

study of personnet management systems as a single, holistic phenomenon that is part of the system of the organization (enterprise) and consists of subsystems, elements and connections

The principle, of obiectivity
research of personnel management systems should be carried out on the basis of scientific correctness and conformity of reality, justice and impartiality, selection of executors of necessary qualification

The nrincinle of science

research is conducted on the basis of modern achievements of science and practice taking into account modern approaches and methods, laws and laws of management of cognitive processes

The principle of functionality

compliance with market relations, features and levels of management

The principle of economic feasibility

research should be cost-effective and increase the efficiency of the personnel management system

The principle of consistency

ensures consistency between the various parts of the management system and with the main goals, objectives, strategy and tactics of the organization, its functioning

The principle of optimality

multivariate elaboration of proposals and selection of the most rational variant of research

Figure 9.3.2. Principles of research of the personnel management system

Developed by the author based on sources [458-461] 
The principles of research of personnel management systems are interconnected, complementary and together constitute a certain system of rules that determine the reliability of research results.

The study of personnel management systems always has a goal, which is divided into sub-goals and objectives. Depending on the goal and objectives of the study are divided into theoretical, empirical and applied. In essence and the need for research aimed at planning, construction, strengthening, development, improvement and operation of personnel management system.

It should be noted that the method of diagnostics of the control system, as well as any other system, should be performed in stages.

The main stages of diagnostics of the personnel management system are shown in Fig. 9.3.3.

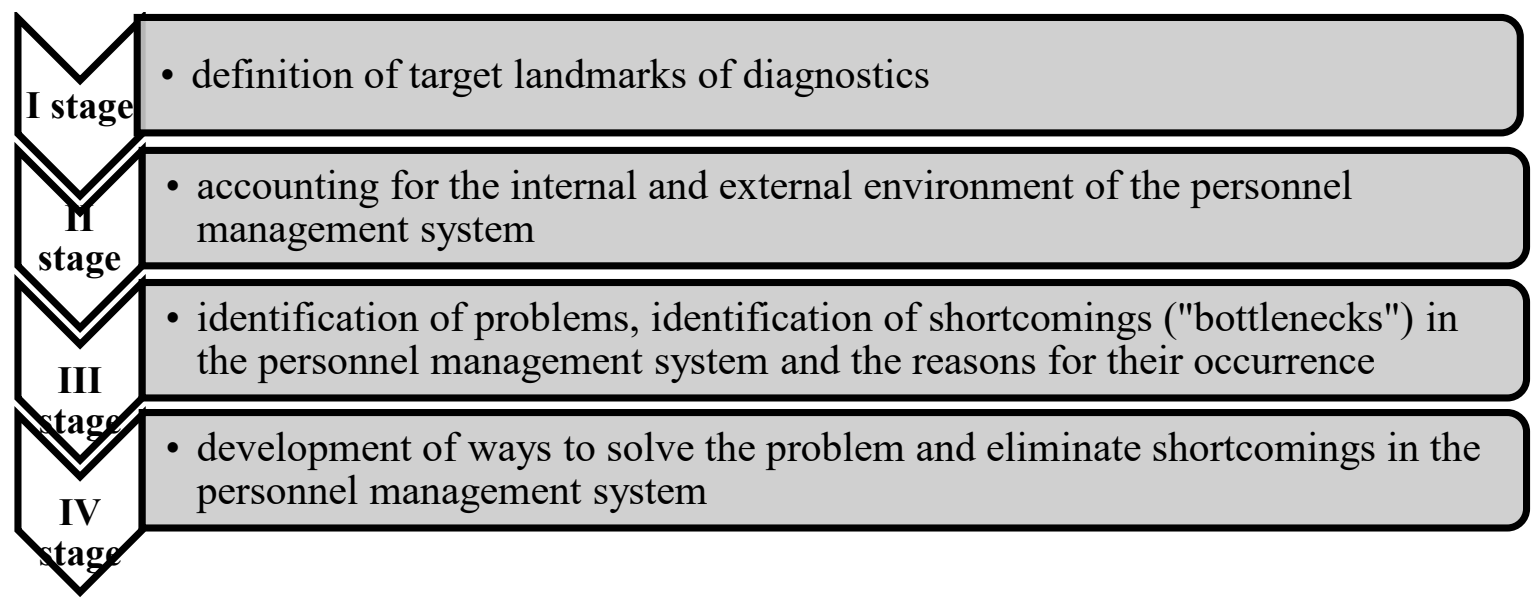

Figure 9.3.3. The main stages of diagnostics of the personnel management system Developed by the author based on sources [464]

I stage "Definition of target landmarks of diagnostics". This stage involves the establishment of goals and objectives that the company should focus on when diagnosing the personnel management system and developing measures to improve the situation.

Stage II "Accounting for the internal and external environment of the personnel management system" involves the analysis of the actual personnel management system and compare it with the desired results. In the course work in the study of personnel 
management system will be used such methods as: express questionnaire; survey of managers; study of documentation; analysis of the external and internal environment of the enterprise. Stage II is the basis for the implementation of stage III "Identification of problems, identification of shortcomings ("bottlenecks") in the personnel management system and the reasons for their occurrence." This stage makes it possible to determine the needs of the personnel management system and set priorities for this process.

Stage IV "Development of ways to solve the problem and eliminate shortcomings in the personnel management system" involves determining the methods and forms of development of the personnel management system that most effectively meet the needs of the enterprise.

When implementing the IV stage of diagnostics of personnel management system, it should be borne in mind that in the modern period of operation of industrial enterprises there is a gradual change of the classical approach to personnel management and the creation of a modern approach to personnel management based on humanistic approach. Comparative characteristics of the classical and modern approach to management are presented in table 9.3.1.

The implementation of such changes in the personnel management system is based on changes in three main important characteristics and functions of personnel policy, which together constitute a new concept of transformation and ensure its competitiveness - changes in staff motivation, development and corporate culture.

These three components (corporate culture, training and development of personnel and their motivation), along with finding ways to improve efficiency, can be considered as the main areas of improvement, development of personnel management. 
Table 9.3.1

Comparison of classical and modern approaches to management

personnel according to the concept of V.R. Vesnina

\begin{tabular}{|c|c|c|}
\hline $\begin{array}{l}\text { The name of the } \\
\text { criterion }\end{array}$ & The classic approach & Modern (humanistic) approach \\
\hline Management style & Authoritarian & $\begin{array}{c}\text { Democratic, welcome initiative, staff } \\
\text { involvement in the personnel management } \\
\text { process }\end{array}$ \\
\hline Personnel & $\begin{array}{l}\text { As a factor of } \\
\text { production }\end{array}$ & As a value, a factor of success \\
\hline Object of management & Staff & Resources, capital, staff \\
\hline $\begin{array}{l}\text { Costs for attracting staff } \\
\text { training, solving social } \\
\text { issues }\end{array}$ & $\begin{array}{l}\text { Minimum; are } \\
\text { considered as "extra" } \\
\text { costs }\end{array}$ & $\begin{array}{l}\text { Maximum; a significant part of the costs is } \\
\text { aimed at the organization of medical care, } \\
\text { creating conditions for recreation, meeting } \\
\text { the needs and development of employees; } \\
\text { costs are considered as investments in the } \\
\text { main source of further income }\end{array}$ \\
\hline Stimulation & Material & $\begin{array}{c}\text { Active application of conditional-intangible } \\
\text { and intangible methods }\end{array}$ \\
\hline $\begin{array}{l}\text { Form of labor } \\
\text { organization }\end{array}$ & Individual & Collective - team work, group \\
\hline $\begin{array}{l}\text { Department in the } \\
\text { structure of the } \\
\text { enterprise dealing with } \\
\text { personnel }\end{array}$ & $\begin{array}{l}\text { Human Resources } \\
\text { Department }\end{array}$ & $\begin{array}{l}\text { Personnel department, social services, } \\
\text { psychologists, coaches, HR managers, all } \\
\text { heads of structural departments subordinate } \\
\text { to the head of the senior staff responsible } \\
\text { for personnel }\end{array}$ \\
\hline \multirow[t]{2}{*}{$\begin{array}{l}\text { The main task of the } \\
\text { personnel department }\end{array}$} & $\begin{array}{l}\text { Ensuring the } \\
\text { availability of } \\
\text { personnel in the } \\
\text { required number, }\end{array}$ & $\begin{array}{l}\text { Ensuring the competitiveness of the } \\
\text { enterprise, its long-term stable development } \\
\text { by }\end{array}$ \\
\hline & $\begin{array}{l}\text { required qualifications } \\
\text { according to the } \\
\text { staffing schedule }\end{array}$ & $\begin{array}{l}\text { regulation of relations between the } \\
\text { production organization and personnel } \\
\text { within the strategy of the enterprise }\end{array}$ \\
\hline
\end{tabular}

Developed by the author based on sources [464, 467-469] 
There are many vectors for the development of this system. All of them are aimed at improving the efficiency of the personnel management system and consist in the implementation of external and internal changes.

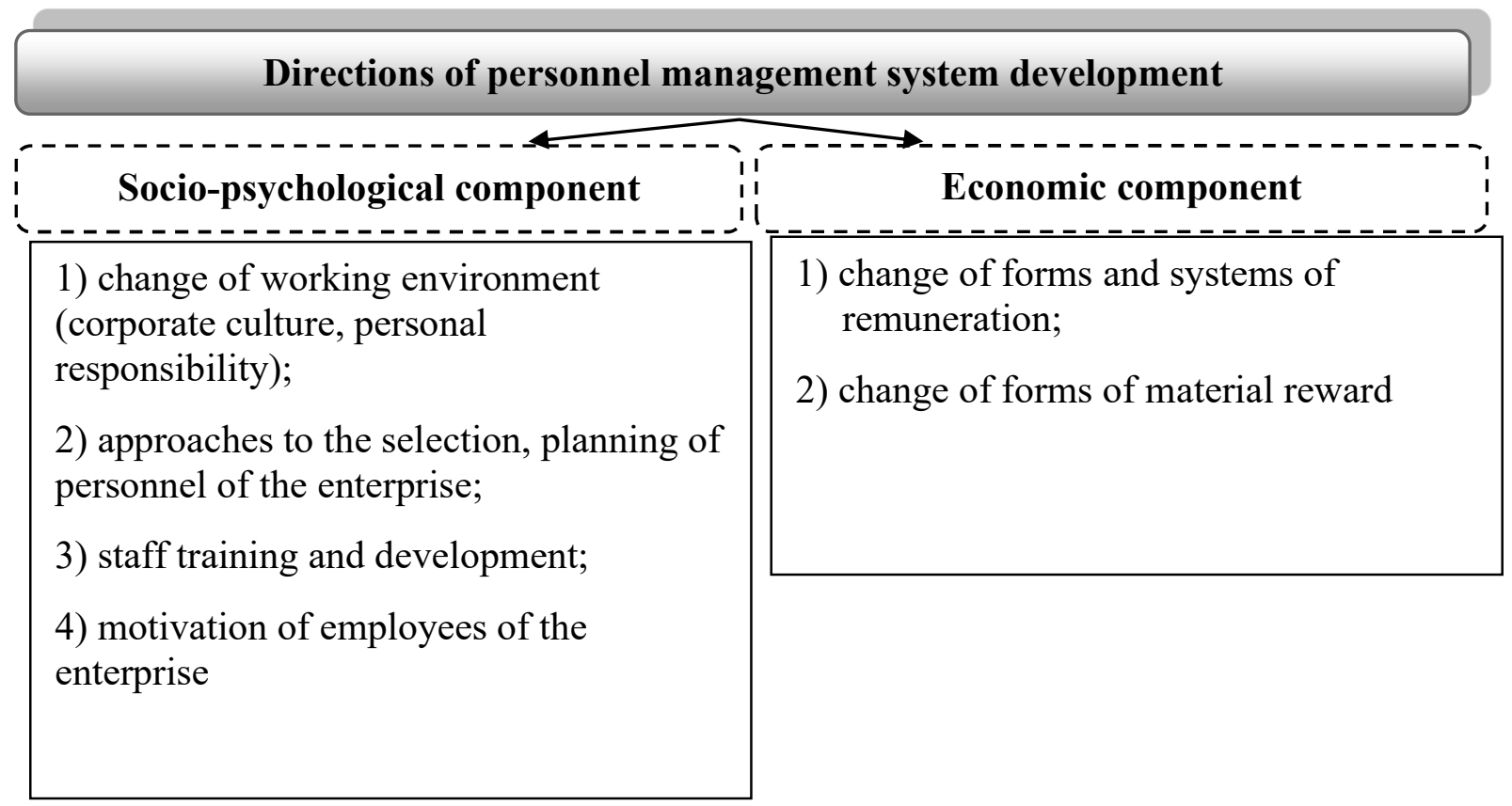

Figure 9.3.5. Directions of development of the personnel management system Developed by the author based on sources [458, 459, 465-469]

External changes include the use of new management systems, a combination of personnel and competitive enterprise development strategy, and so on. Internal changes of the personnel management system - creation of the corresponding corporate culture at the enterprise, training and development of the personnel, increase of its motivation, etc. 